Hornes, M. - Saberes, tramas y significados del dinero: una aproximación etnográfica a las transferencias monetarias condicionadas; en REA No XXI, 2015; Escuela de Antropología - FHUMYAR - UNR

Saberes, tramas y significados del dinero: una aproximación etnográfica a las transferencias monetarias condicionadas

\author{
Martín Hornes (CESE - UNSAM) \\ m_hornes@hotmail.com
}

\title{
Resumen
}

Los programas de TMC se han convertido en las principales políticas sociales de Argentina y América Latina. Distintos trabajos académicos han abordado sus características, sin embargo, pocos estudios han explorado los significados sociales del dinero transferido.

A través de este trabajo analizaremos los significados que envuelven al dinero transferido a partir de las TMC. Contemplando las definiciones que intentan imponer ciertos saberes expertos, recorreremos escenas significativas en la aplicación de un programa de TMC municipal. Nos interesa vislumbrar las tramas de actores y prácticas -expertos, mediadores sociales y hogares receptores- que participan en la construcción de los significados del dinero.

Palabras claves: transferencias monetarias condicionadas- saberes y prácticasmediadores y hogares- dineros plurales.

Knowledge, patterns and meanings of money: an ethnographic approach to conditional cash transfers

\begin{abstract}
TMC programs have become major social policies in Argentina and Latin America. Various academic works have addressed their characteristics, however, few studies have explored the social meanings of transferred money. Through this work, we will analyze the meanings involving money transfe-
\end{abstract}


Hornes, M. - Saberes, tramas y significados del dinero: una aproximación...

rred from the TMC. Looking at the definitions that try to impose certain expert knowledge, we will visit significant scenes in the implementation of a programme of municipal TMC. We want to glimpse wefts of actors and practices - experts, social mediators and receiving homes - participating in the construction of the meanings of the money

Key words: cash transfers conditional - knowledge and practices - mediators and homes - plural moneys.

\section{Palabras introductorias}

Estábamos por terminar la entrevista y $\mathrm{Julio}^{1}$ repregunta: “ ¿Cómo era ese programa en el que tú te desempeñabas como trabajador social?". Entonces le recuerdo que estaba destinado a adolescentes en situación de vulnerabilidad social que, asistiendo a contra turno de la escuela a una serie de intervenciones educativas y recreativas, accedían a una beca mensual que ascendía a $\$ 150$ (pesos) ${ }^{2}$. La descripción del Programa "Jóvenes"” despierta una anécdota reciente:

"Justo estaba el otro día en México en uno de esos encuentros, con una mesa larga de sesenta personas... había gente involucrada al Prospera ${ }^{4}$. Entonces yo les pregunto a las mujeres que estaban allí cuántas de ellas tenían hijos o hijas de 16 años: varias responden que yo, que yo. Ellas no sabían nada pero desde el Banco $^{5}$ estamos pensando en un elemento nuevo: se trata de dejar de darles el dinero a la mujer responsable o madre y comenzar a dárselo a los hijos, por considerar que ya son altruistas para tomar algunas decisiones. Entonces, estamos pensando en darles el dinero directamente a los jóvenes y para eso pensamos en un proyecto piloto de entregarles a los de 16 y 17 años, aquellos que ya están en el nivel de la preparatoria. Pero como la gente no sabía nada de todo esto empezó a opinar. La primera de ellas dijo que 'estaba bueno, que los jóvenes ya tenían sus gastos, sus 
cosas'. Otra en un extremo de la mesa dijo lo mismo: 'que los jóvenes son responsables'. Hasta que una de ellas levantó la mano y dijo: "pero nada mejor que una madre para saber que necesita su hijo'. Y allí la cosa se puso entretenida... (risas) se desató toda una discusión donde decían: 'que era un problema', 'que en que lo iban a gastar los chicos', 'que era un riesgo', 'que cómo controlarlos' y demás cuestiones. Entonces, intervino el trabajador social que era el que estaba coordinando el grupo: 'la verdad que es divertido, porque ustedes no quieren darles responsabilidades a sus hijos pero después cuando no saben qué hacer nos vienen a pedir a nosotros los trabajadores sociales: 'habla con él que no me quiere hacer caso, que no quiere ir a la escuela'. Entonces: ¿Qué tanto es la madre la que mejor sabe para su hijo si después no pueden resolver?"'.

Esta escena etnográfica es una reconstrucción de los últimos minutos de una entrevista realizada a un economista del área de protección social de uno de los principales organismos multilaterales de América Latina y El Caribe. Seleccionamos este fragmento para introducir el objetivo central de este artículo: explorar las tramas de sentidos y los múltiples significados que envuelvenal dinero transferido a partir de las políticas sociales.

Durante la última década, proliferaron en la región de América Latina distintas políticas sociales centradas en transferencias monetarias condicionadas (TMC). Estas intervenciones guardan similitudes: a) suplantan la tradicional provisión de bienes y servicios por la entrega de dinero en efectivo a los sectores más vulnerables y, b) establecen condicionalidades en materia de salud y educación sobre los menores pertenecientes al hogar (controles sanitarios y asistencia escolar) (Cecchini y Madariaga, 2011). 
Hornes, M. - Saberes, tramas y significados del dinero: una aproximación...

Una inmensa cantidad de trabajos de ámbitos gubernamentales y académicos han explorado y caracterizado las transformaciones que implican la implementación de estas políticas sociales. Los abordajes han problematizado la reconstrucción de los esquemas de protección social (Ringold y Rofman, 2008), el perfil de las poblaciones beneficiarias (Marchioni y Conconi, 2008), las dimensiones del género (Franzoni, 2008), los impactos en índices de pobreza e indigencia(Agis y Cañete, 2010), como así también, en la transformación de pautas y acceso al consumo de los sectores más pobres(Kliksberg y Novacovs$\mathrm{ky}, 2015)$. En este trabajo nos interesa aproximarnos a una perspectiva poco explorada, indagando sobre la trama de significados sociales que adquiere el dinero entre los distintos actores involucrados en las políticas de transferencias monetarias.

En distintos trabajos hemos abordado cómo el dinero transferido a partir de las políticas sociales adquiere sentidos plurales, pese a que distintos saberes expertos intentan imprimirle una definición unívoca (Hornes, 2015). Nuestros hallazgos etnográficos nos permiten afirmar que el dinero proveniente de los programas de TMC atraviesa distintos procesos de disputa al interior de los hogares receptores. Más allá de la performatividadprogramática que propagan los expertos, nuestros trabajos exploran como los diferentes miembros definen los significados y usos del dinero lidiando con negociaciones en torno a las construcciones sociales del género e interpretaciones intergeneracionales sobre el mismo (Hornes, 2014b).

En esta oportunidad nos interesa reconstruir las interpretaciones sobre el dinero de los distintos actores relacionados en la implementación de las políticas de TMC. Para tal fin, utilizaremos una distinción analítica entre actores expertos ${ }^{6}$, mediadores sociales ${ }^{7} \mathrm{y}$ hogares receptores. No es nuestra intención presentarlos como acto- 
res distantes en el mundo social, sino que se trata de reconocer e indagar sobre los distintos saberes y prácticas que cada grupo moviliza para dotar de significado al dinero proveniente de las TMC.

Para guiar nuestro análisis nos valdremos de los insumos teóricos pertenecientes al campo de los estudios sociales de la economía y los significados del dinero. Durante las últimas dos décadas, distintos trabajos académicos pertenecientes a la teoría de la regulación han reinterpretado los significados de la moneda más allá de su valor uso, cambio y reserva de valor (Therét, 2015). A estas relecturas, se suman los hallazgos de la antropología y la sociología económica sobre los significados y usos sociales del dinero desde la década del 60' hasta esta parte (Bohannan, 1967; Dalton, 1967; Bloch y Parry, 1989; Dodd, 1994; Guyer, 1994).

Sin lugar a dudas, la aparición de la obra de Viviana Zelizer titulada "Los significados sociales del dinero" (2011) inscribe un nuevo horizonte de indagación sobre tales interpretaciones. En sus distintos trabajos (Zelizer, 2011 y 2009) demostró los múltiples significados personales, sociales y morales que pueden acompañar las transferencias de dinero. Sus hallazgos muestran cómo el dinero puede introducir distinciones, disputas y negociaciones incluso en las relaciones de mayor confianza e intimidad y, en determinados casos, empuja a sus participantes a establecer límites específicos para garantizar diferentes transferencias.

Siendo que nuestra indagación comprende los múltiples significados que adquiere el dinero transferido hacia los sectores populares, resultanineludibles los trabajos de Ariel Wilkis (2014 y 2013). El autor ha explorado con detenimiento una multiplicidad de prácticas económicas y significados del dinero en los sectores más postergados, demostrando las múltiples conexiones y significados 
Hornes, M. - Saberes, tramas y significados del dinero: una aproximación...

que el dinero puede alcanzar entre actores supuestamente disímiles. Los diferentes dineros (militados, prestados, donados y ganados) nos permiten compartir una de las premisas centrales de su trabajo: los múltiples significados del dinero aportan elementos para explorar e interpretar concepciones sobre el orden social (Wilkis, 2013).

Desde este punto de vista reconstruiremos las tramas de sentidos y los significados plurales que envuelven al dinero transferido a partir de las políticas sociales. Daremos cuenta de las definiciones que los expertos intentan imponer a través de los esquemas programáticos y, a su vez, completaremos dicha indagación explorando dos escenas etnográficas sobre eventos significativos ${ }^{8}$ de intervención de los "agentes estatales en el terreno" (Dubois, 2014).

El trabajo de campo que da lugar a este artículo forma parte de las distintas actividades relacionadas con mi tesis de Maestría en Antropología Social (Hornes, 2013). Como mencioné al inicio, el ingreso al campo se vio facilitado a partir de mi inserción como trabajador social en un programa de TMC destinado a adolescentes en situación de vulnerabilidad social. El mismo se llevó adelante en un barrio del Municipio de Avellaneda, localidad situada al sur del Área Metropolitana de la Ciudad de Buenos Aires, Argentina9 . Nos referiremos al barrio en cuestión bajo el nombre ficticio de Villa Asunción.

El artículo se organiza de la siguiente manera. En un primer apartado, recorreremos brevemente el surgimiento de las políticas de TMC en la República Argentina. Introduciendo las particularidades del caso demostraremos que guarda una similitud con otras políticas de TMC de la región: los saberes expertos intentan imprimirle una definición unívoca al dinero transferido. En un segundo apartado, desarrollaremos dossituaciones de intervenciónsobre eventos significativos en la aplicación del programa “Jóvenes". Estas nos permiti- 
rán observar la diversidad de actores e interacción que participan en la construcción delos significados del dinero. En un tercer y último apartado, reflexionaremos respecto de las múltiples tramas de sentidos y significados que atraviesan al dinero transferido a partir de las políticas de TMC.

\section{Significados y prácticas de expertise: ¿El caso argentino?}

Cuando abordamos el caso argentino observamos que los programas de TMC surgen en el año 1997 y tienen como primera medida el Plan Trabajar, el cual se trataba de un programa destinado a poblaciones que se encontraban desempleadas en un contexto económico y social donde la desocupación crecía de forma acelerada. Tras la crisis económica/ financiera del año $2001 \mathrm{y}$, con un nivel de desocupación que alcanzaba a más del $20 \%$ de la población del país, surge el denominado Plan Jefes y Jefas de Hogar Desocupados.

La introducción del Plan Jefes y Jefas de Hogar en Argentina implica la llegada de algunas de los atributos de los programas de TMC como los conocemos en la actualidad: la transferencia de una suma mensual de dinero ( $\$ 150$ por mes) a condición de cumplir con una contraprestación laboral de una determinada cantidad de horas semanales ${ }^{10}$. Es interesante señalar que este tipo de condiciones comienzan a ponerse en juego a partir de los intereses de los organismos que proponen y financian dicha política -en este caso el Banco Mundial- a los fines de que las entregas de dinero estén justificadas a partir de una actividad ligada al trabajo.

A partir del año 2004 se multiplican las políticas sociales de TMC destinadas a las poblaciones desocupadas. A partir del proceso de desintegración que comienza a atravesar el Plan Tra- 
Hornes, M. - Saberes, tramas y significados del dinero: una aproximación...

bajar, se despliegan una serie de intervenciones que dan lugar al surgimiento de una serie de programas: el Plan Familias, el Plan Manos a la Obra, y el Plan de Seguro de Capacitación y Empleo. Para la misma época pueden mencionarse otros programas de TMC como: el Plan Barrios Bonaerense, el Programa de Capacitación y Empleo y el Plan de Empleo Comunitario. Incluso a inicios de 2008, el emblemático Plan Vida radicado en la Provincia de Buenos Aires e impulsado por Hilda "Chiche" Duhalde desde el año 1994, transforma su estrategia de intervención suplantando la entrega de alimentos por una suma de dinero según la cantidad de hijos por beneficiario.

Durante el año 2009 surgen los dos programas de mayor envergadura en términos de TMC. Nos referimos al Programa Ingreso Social con Trabajo "Argentina Trabaja" bajo la dependencia del Ministerio de Desarrollo Social de la Nación, y a la Asignación Universal Por Hijo para la Protección Social (AUH) bajo la dirección de la Administración Nacional de la Seguridad Social (ANSES).

En el primer caso, el programa "Argentina Trabaja" surge como una propuesta de generación de empleo para las poblaciones de los sectores más vulnerables. La propuesta implica la promoción de la organización cooperativa entre los beneficiarioscon el objetivo de que realicen tareassociales o de infraestructura en sus comunidades de origen. Entre sus componentes, se destaca la posibilidad de que los miembros del programa finalicen sus estudios (primarios o secundarios) y accedan a la formación en oficios y/o capacitaciones, a través de la articulación con otros programas laborales y educativos. En la actualidad, los beneficiarios cumplen con una carga horaria semanal de 20 horas (4 horas diarias) y el monto de la transferencia ascienda a $\$ 2.600$ por mes ${ }^{11}$. 
En el segundo caso, la AUH surge como una iniciativa para "equiparar los ingresos de aquellos niños cuyos padres no estuvieran incorporados al mercado de trabajo formal, y por ende, "no recibieran la asignación por hijo estipulada en el régimen contributivo de asignaciones familiares" (MECON, 2009:6). En la actualidad, el monto de las transferencias asciende a $\$ 962$ por $\operatorname{mes}^{12}$, por hijo,debiendo cumplircon las condicionalidades establecidas en términos de concurrencia escolar y controles de salud. De esta manera, la AUH adquiere características similares a otras TMC de la región: se centra en transferencias directas de dinero, específicamente fundamentadas y focalizadas sobre los menores pertenecientes al hogar, y transferibles a los mayores responsables ${ }^{13}$.

Nos interesaba mencionar las particularidades del caso argentino para observar que existe una homogeneidad entre los criterios de condicionalidad que estructuran las políticas de TMC. Al igual que sucedió en otros países de la región de América Latina, los saberes expertos en políticas sociales intentaron imprimirle una definición unívoca al dinero, apoyándose en las nociones de condicionalidad que acompañan las transferencias. Los saberes expertos refieren a la noción de "capital humano", "la relevancia de las transferencias por género" y la "aceptabilidad política" (Banco Mundial, 2009) para construir una definición performativa sobre los significados del dinero.

Los expertos en TMC han bregado para que la noción de condicionalidad que hace posible las transferencias de dinero gire en torno a dichos conceptos. Así, proponen pensar la transferencia como "condición de que esos hogares realicen inversiones, previamente especificadas, en el capital humano de los menores pertenecientes al hogar" (Banco Mundial, 2009: 1). La noción de capital humano conlleva al cumplimiento de una serie de condiciones referidas a: 
Hornes, M. - Saberes, tramas y significados del dinero: una aproximación...

1) educación: controles de matrícula escolar y complementariedad educativa; y 2) salud: controles periódicos en instituciones públicas (Ringold y Rofman, 2008).

En la misma línea argumentativa han sostenido la preferencia de la mujer como portadora de la titularidad del beneficio (Marchionni y Conconi, 2008). Distintos documentos sostiene que dicha condición conjuga dos cuestiones centrales: el género del titular y el uso del dinero en el hogar receptor. Aseguran que "las mujeres tienden a dar un mejor uso a los fondos que los hombres" (Banco Mundial, 2009: 11), y que este control en el dinero se convierte en "una manera de abordar disparidades de género ineficientes e injustas" (Banco Mundial, 2009: 10).

En último lugar, los expertos sostienen que distintas encuestas constatan que "los contribuyentes estén más dispuestos a apoyar un programa de transferencias" (Cruces y Rovner, 2008). Desde esta perspectiva, la mayor disposición de los contribuyentes tiene su razón de ser en el hecho de que "las iniciativas incluyen medidas para mejorar el bienestar de los niños" (Banco Mundial, 2009: 2), y "después de todo, es difícil decir que los niños tienen la culpa de ser pobres" (Banco Mundial, 2009: 11).

Con este breve apartado buscamos escenificar que la definición conceptual de condicionalidad y los debates que a dicho término conciernen, atraviesan de forma completa todo el esquema de planificación de los programas de TMC. Observar el caso argentino no es mirar un caso aislado, sino poder vislumbrar que las condiciones sobre el dinero forman parte estructural de las etapas de diseño, ejecución, monitoreo y evaluación de los diferentes programas existentes en la región de América Latina y El Caribe. En este sentido, los saberes expertos han organizado las transferencias hacia los 
hogares pobres intentado demarcar significados y usos específicos sobre el dinero.

En el próximo apartado demostraremos la trascendencia de los saberes expertos observando distintas interacciones de los mediadores sociales en el territorio. Nos interesa percibir las diferencias, similitudes o reinterpretaciones que se pueden hilvanar sobre los significados del dinero en instancias concretas de aplicación de un programa de TMC.

\section{Desayuno de trabajo}

Son las 11 hs y Pamela-Directora de Inclusión Social del Municipio- da por comenzado el "Desayuno de Trabajo". Nos encontramos en una mesa rectangular, en un extremo se ubica un proyector donde comienza a rodar el video institucional del programa "Jóvenes". Este último muestra una presentación breve del programa, imágenes de alguna sede, palabras de la directora de Inclusión Social y distintas voces de sus participantes: en primer lugar los adolescentes, luego algunos de los tutores y, por último, algún profesional del área social y educativa.

Una vez finalizada la proyección, Pamela retoma la palabra: "Nos encontramos hoy aqui para disfrutar de una jornada de trabajo muy importante para nosotros. Es una oportunidad para poder compartir con ustedes el funcionamiento del Programa Jóvenes”. En la mesa de la sala de reuniones de una de las empresas más próximas a Villa Asunción, se encuentran algunos de los dueños y representantes de distintas empresas radicadas en el barrio y sus periferias. Se trata de industrias de alimentos, curtiembres y reciclaje, las cuales colaboran con el programa "Jóvenes" para el pago de algunas de las becas mensuales que reciben los adolescentes. 
Hornes, M. - Saberes, tramas y significados del dinero: una aproximación...

Pamela vuelve a tomar la palabra para introducir las características del programa. Se toma cerca de veinte minutos para mencionar la cantidad de adolescentes que participan, las cinco sedes ubicadas en distintos barrios, las actividades que allí se realizan, los profesionales que conforman los equipos, los montos de dinero transferidos en calidad de "becas", las condicionalidades educativas demandadas por el programa, etcétera. Los presentes escuchan atentos, casi ni intervienen y, si lo hacen, es para bromear o hacer algún comentario sobre una imagen.

Luego de la exposición de Pamela llega mi turno. Comienzo presentando la cantidad de adolescentes pertenecientes a Villa Asunción que participan en el "Jóvenes" y las actividades que allí realizan, destacando el conjunto restante que esperan ser admitidos al programa por falta de becas (cerca de 100 en ese momento). Continúo resaltando que, al iniciar nuestras actividades, un número importante de adolescentes no se encontraba escolarizado. Un cuadro de doble entrada me permite acompañar esa información con cifras y porcentajes del antes y después de la intervención del "Jóvenes". La información demuestra que el programa no sólo revirtió la situación de aquellos adolescentes no escolarizados, sino que, además, tuvo un efecto positivo sobre las trayectorias educativas del resto de los jóvenes en términos de permanencia y/o repitencia.

Luego de mostrar algunos de los alcances en materia de educación, cedo la palabra a Amalia, encargada del área salud. Amalia comienza la exposición haciendo hincapié en las deficitarias condiciones de hábitat y salud de los vecinos de Villa Asunción. Esta caracterización le permite reconocer las problemáticas de salud más relevantes que presentaban los "Jóvenes" y demostrar como el programa logró mejorar tales situaciones en el plazo de un año. Breve- 
mente expone resultados de charlas educativas en materia de salud con padres y adolescentes, jornadas de vacunación en los hospitales zonales, sobre cuidados anticonceptivos, alimentación, etcétera. La información es precisa y consistente, muchos de los presentes arrojan gestos de aprobación.

Cuando Amalia finaliza su exposición, Pamela me sugiere que comente "algunas de las actividades que están realizando las cooperativas". Introduzco a los presentes alguna información de contexto para que comprendan que se trata de un programa social denominado "Argentina Trabaja", el cual fomenta el cooperativismo/ asociativismo entre los vecinos que se residen en barrios postergados y se encuentran desocupados. Mencionó que una de las estrategias del programa "Jóvenes" fue articular con esta política social para que los padres y/o hermanos adultos de los adolescentes pudieran acceder a un ingreso económico con una actividad de tipo laboral. Cierro mi exposición mostrando algunas fotos de los cooperativistas trabajando en la mejora de veredas y lugares comunes de Villa Asunción.

Nuestras exposiciones y la información presentada resultan contundentes, algunos aplauden y los gestos de aprobación van acompañados de palabras como: "qué lindo trabajo", "para nosotros es muy grato porque sabemos de las necesidades del barrio", "conocemos a algunos de los chicos de las fotos", etcétera. Agradecemos el tiempo y la predisposición, mientras comienzan a surgir algunas inquietudes sobre como "seguir trabajando juntos".

Antes de que la reunión se diluya, Pamela menciona que "el cierre es con una propuesta para que se vayan pensando cómo nos pueden seguir ayudando". Sus palabras sorprenden tanto a los presentes como a Amalia y a mí. Brevemente Pamela expone una propuesta de "Egreso del programa Jóvenes" destinada a aquellos adolescentes 
Hornes, M. - Saberes, tramas y significados del dinero: una aproximación...

que alcanzan la mayoría de edad (18 años) y al egresar del programa puedan "insertarse en el mercado de trabajo". Se trata de una instancia de "capacitación laboral de seis meses" articulada con algunas de las empresas del barrio y considerando la opción de incorporación laboral permanente una vez finalizado el plazo de aprendizaje.

El encuentro termina con la propuesta de egreso esbozada pero sin más tentativas. Mientras nos retiramos y de forma un tanto picaresca, Pamela nos comenta entre susurros: "esperemos haberlos sensibilizados un poco... no nos olvidemos que son empresarios".

\section{Baja controversial}

En marzo de 2009 estuve encargado de realizar una serie de altas al programa “Jóvenes". Las mismas fueron el resultado de más de 30 entrevistas de admisión realizadas durante los meses de enero y febrero del mismo año. A partir de marzo ingresaron al programa 10 adolescentes con distintas trayectorias familiares y educativas. Recuerdo que en ese momento Javier, el coordinador de la sede donde trabajaba, afirmaba: "un éxito las altas Martín: distintos perfiles de pibes que por diversos motivos pueden participar del programa".

Los adolescentes que ingresaba al programa eran seleccionados según variables que daban cuenta de distintos niveles de criticidad en cuanto a su situación de vulnerabilidad social ${ }^{14}$. Entre ellos se encontraba Juan, de unos 14 años de edad, con una trayectoria escolar de constante repitencia. Juan vivía junto a sus padres y una hermana menor de cuatro años, en uno de las zonas del barrio conocida como "el pasillo de los tucumanos", en relación a la provincia de origen de algunos de sus vecinos. Natalia, su mamá, trabajaba como empleada doméstica y su papá en un taller mecánico.

Al principio, Juan participaba dos veces por semana en las actividades que se desarrollaban en las instalaciones del "Jóvenes". Asis- 
tía a un taller de murga y, con muchas más dificultades, participaba de los espacios de apoyo escolar de matemática y lengua. Además, todos los días almorzaba en las instalaciones del programa antes de asistir al colegio. Era todo un logro mantener esos dos días semanales de participación, él siempre argumentaba: "que querésTincho... a mi nadie me despierta, mis viejos se van a trabajar desde temprano”.

Con el correr de los meses su participación fue resultando cada vez más problemática. En algunas ocasiones Juan era expulsado de las actividades que realizaba por "mala conducta". En otras ocasiones no asistía al programa por días y sólo pasaba para que "me den la comida". Cuando visitábamos su casa, tomábamos conocimiento de que había estado detenido en alguna comisaría o "estaba de gira", como decía su madre cuando se ausentaba por varios días de la casa.

Si bien fueron varios los episodios problemáticos que involucraban a Juan, en el mes de octubre la situación se volvió insostenible. En la misma semana Juan asistió al programa con un cuchillo para amenazar a un compañero y luego había insultado a distintos miembros del equipo técnico del programa. Tras una serie de idas y vueltas, se convocó a una reunión de equipo técnico para evaluar la continuidad de Juan. Karina, una de las técnicas del equipo y encargada del área de educación, argumentaba: "la verdad es que ya se hace insostenible la participación de Juan. No respeta ninguna de las normas de convivencia, no respeta a ninguno de sus compañeros, no respeta nada". Pese a las controversias entre los miembros del equipo técnico, decidimos sostener su participación de forma condicionada por el plazo de un mes. Sin embargo, esto implicaba una "reducción en el monto de la beca" de Juan por "mal comportamiento" y mi compromiso como trabajador social de realizar una visita domiciliaria al hogar de la familia. 
Hornes, M. - Saberes, tramas y significados del dinero: una aproximación...

Durante esas semanas conversé varias veces con la madre de Juan pero nunca pude dar con su padre. Luego de reiterados intentos frustrados, Natalia me confirmo que estaban separados desde hacía un tiempo:"no me gusta que lo sepan en el barrio... Juan debe estar mal por eso también". Intenté pensar alguna estrategia de intervención junto a ella pero se encontraba totalmente desanimada: "yo ya no sé qué hacer con Juan... ya no sé. A mí no me hace caso, al papá cuando lo ve pero hasta ahi nomás. La directora me dijo que ya este es el último año que me lo acepta en el colegio".

Las conversaciones con Juan resultaban más complicadas. El llamado de atención sobre la "reducción en el monto de la beca" propicio alguna conversación, aunque al mencionarle los motivos se molestó y reaccionó quitándole importancia: "Qué onda con vos Tincho! No pasa nada... hacemos más guita pinchando alguno que con esta gilada". Quedaba claro que la "gilada" refería al programa "Jóvenes", por lo que le pregunté sobre "pinchar a alguno": "vos sabes Tincho... dale vos sabes... Robando guacho, pegando un auto, una moto ... algo. Después lo vendemos allá en Gerli”.

Noviembre fue el último mes que Juan estuvo vinculado al programa "Jóvenes". La baja del programa se decidió después de que agrediera nuevamente a un compañero y se robara alimentos para la merienda. En la reunión de equipo técnico, Karina volvía a señalar: "ya no le importa nada chicos... ni siquiera que le descontemos plata de la beca. No se dan cuenta... debe sacar más guita choreando y no le importa el programa, no le importa nada!". En la misma línea, Tomas, docente del taller de deportes mencionaba: "Que siga tiene que ver con la plata y no tiene que ver. ¿Suponete que en la casa de Juan la necesiten? Acá sabemos que hay otros pibes del barrio que también la necesitan. Y, por otro lado, ya no hay manera con sus 
formas... así no se puede seguir: no tiene ningún registro del otro, del respeto, de los valores... nada”.

Nuevamente la tarea de visitar a la familia me fue encomendada, pero esta vez para realizar la baja definitiva del programa. Estábamos sentados en la mesa del comedor de la casa mientras se lo comunicaba a Juan y a su mamá. La reacción de Juan fue un tanto violenta aunque se lo notaba angustiado. No pudo sostener quedarse en el lugar mientras terminaba de justificar la decisión a la que habíamos llegado y, con lágrimas en los ojos, se levantó y salió por la puerta gritándome: "Para vos a haber balas, Tincho!'. Su mamá trato de retenerlo pero fue inevitable la huida.

Cerramos el encuentro con Natalia. Mientras le contaba de los múltiples conflictos con Juan y de la decisión consensuada con el resto de los miembros del equipo técnico, ella me interrumpió para agregar: "Pero sabes que... hay algo que no entiendo: el día que aceptaron a Juan en el programa me dijiste que estaba pensado para chicos como él, con situaciones similares a las de él”.

\section{Palabras finales}

"Desayunos" o "Almuerzos de trabajo", "Reuniones para firma de acuerdos- compromiso de becas", "Inscripciones en lista de espera", "Visitas domiciliarias", "Entrevistas de admisión”y otra serie de situaciones podrían formar parte de la reconstrucción etnográfica que ensayamos en este trabajo. Eventos que refieren a distintas instancias de interacción con actores diversos vinculados al "Jóvenes": desde empresarios hasta directivos municipales, pasando por equipos técnicos, distintos hogares y los propios jóvenes aspirantes o pertenecientes al programa.

Como mencionamos en la introducción, también se trata de eventos que forman parte de la cotidianeidad de la implementación 
Hornes, M. - Saberes, tramas y significados del dinero: una aproximación...

de un programa de TMC. Cotidianeidad que, observada a la distancia, arroja algunas premisas significativas para analizar las tramas de sentido y los significados que envuelven al dinero proveniente de las TMC. Mucho más lejos de esos eventos podemos ver que existían saberes y prácticas diversas.

Escenas como "Desayuno de trabajo" relevan algunas cosas inquietantes. La presentación del programa, mostrar los efectos deseados y algunos de los concretados- como ser, la reinserción y la terminalidad educativa o las coberturas de salud- se emparentan bastante con aquellas premisas arrojadas por los saberes expertos. De forma similar, quienes nos desempeñábamos como mediadores sociales en aquellos espacios de interacción con los empresarios, propagábamos las condiciones para hacer posibles las transferencias de dinero: aumentar el capital humano de los adolescentes para romper con la pobreza intergeneracional.

Podríamos seguir argumentando en el mismo sentido, sobre todo si contemplamos que el "Desayuno de trabajo" finalizaba con una "propuesta de egreso" del programa "Jóvenes". Tal como señalara Pamela entre susurros, no sólo había que "sensibilizar" a los empresarios presentes sino,además, había que convencerlos de la efectividad de la "propuesta de egreso" vía inserción en el mercado de trabajo formal. Esquema que guarda cierta similitud con la "aceptabilidad política" a la cual ser refieren los saberes expertos: los empresarios estarían más dispuestos a colaborar en una propuesta que favorezca las condiciones de vida de los jóvenes.

Entonces, aquellas que parecían particularidades de un programa de TMC de alcance municipal, tenían su razón de ser en esquemas programáticos que excedían el universo de Villa Asunción y la implementación del "Jóvenes". Con esto no estamos afirmando que los 
saberes expertos cumplen con su performatividad de manera completa o total. Por el contrario, escenas como la trayectoria de Juan en el programa y su "baja controversial", nos invitan a reflexionar sobre la disrupción que se produce en los espacios concretos de interacción y producción de sentidos sobre el dinero y las políticas sociales.

"Me dijiste que estaba pensado para chicos como él, con situaciones similares a las de él”, mencionaba Natalia finalizando nuestro encuentro. Lo cierto es que no se equivocaba porque Juan cumplía con muchas de las variables de vulnerabilidad que establecía el programa "Jóvenes", aplicaba al perfil del beneficiario. Lo que Natalia no sabía era que, parte de las consideraciones sobre la situación de Juan en el programa, estaban atravesadas por las disputas y evaluaciones morales que realizábamos los propios técnicos del programa. Las apreciaciones de muchos de los técnicos hacían hincapié en la evaluación de sus comportamientos e incluso sobre los significados del dinero.

Hallazgos etnográficos como los de VincentDubois (2014) y ManiTebetMarinis (2015) nos aportan herramientas para reflexionar sobre la situación de Juan. Las evaluaciones que realizábamos los técnicos iban mucho más allá de la situación de vulnerabilidad. Cuando los técnicos evaluábamos dimensiones como los "valores", "el respeto" o "la necesidad", introducíamos elementos que no provenían del campo profesional. Es decir, en las evaluaciones que realizábamos los profesionales se incorporaban las categorías de percepción y apreciación que formaban parte de nuestroshábitus, investidos con expresiones técnicas (Dubois, 2014: 144-145).

En este sentido, también podemos considerar que muchas de las interacciones iban más allá del intento de imprimir condicionalidades. Al movilizar saberes y prácticas en los espacios en que los 
Hornes, M. - Saberes, tramas y significados del dinero: una aproximación...

mediadores sociales interactuábamos cotidianamente, también estábamos inculcando significados morales y socialessobre el dinero. De alguna manera, intentábamos negar el dinero que efectivamente Juan conseguía a través del delito, introduciendo otro dinero para "moralizar" sus prácticas y disciplinar su comportamiento de acuerdo a nuestros propios valores morales.

Florence Weber y CarolineDufy(2009) aseguran que la etnografía económica posee dos virtudes metodológicas: 1) permite comprender que las prácticas económicas de los actores no están separadas del mundo social y, 2) nos otorga la posibilidad de trascender cualquier definición establecida a priori para interpretar las "prácticas e ideas ordinarias" (Neiburg, 2008) o "cálculos ordinarios" (Weber, 2002) que los agentes movilizan en distintos escenarios sociales.

En analogía con las premisas de las autoras, este trabajo fue un intento por trascender los saberes expertos en políticas sociales, identificando interacciones concretas y tramas de sentido, las cuales nos invitan a continuar explorando la pluralidad de significados que hilvanan el dinero transferido a partir de las TMC.

Recibido: 20/11/15

Evaluado: 03/03/16

Versión Fianl: 03/03/16

\section{Notas}

1. Utilizaremos nombres ficticios para referencias institucionales y personales a los fines de salvaguardar la identidad de quienes que brindaron su participación en la investigación. Con comillas y cursivas identificaremos citas textuales de entrevista o la recuperación de relatos y categorías etnográficas. Utilizaremos solo cursivas cuando se trata de referencias documentales o bibliográficas. 
2. Cerca de 10 dólares estadounidenses según la cotización actual de la moneda en la República Argentina.

3. Bajo la denominación "Jóvenes" nos referiremos a un programa social de alcance provincial destinado a adolescentes de 12 a 21 años que se encuentran en situación de vulnerabilidad social. Para más referencias: Hornes (2014a).

4. Refiere al programa de transferencias monetarias condicionadas emblema de México y a partir del cual comienzan a afianzarse en la región las políticas con estas cualidades. En la actualidad lleva el nombre de Programa de Inclusión Social "PROSPERA", sin embargo, sus orígenes datan del año 1997 cuando se lo denominaba Programa "Oportunidades". 5. Refiere a uno de los organismos multilaterales y de desarrollo más importante de la región de América Latina y El Caribe.

6. Seguimos la definición de Morresi y Vommaro (2011) para referirnos a los saberes expertos y campos de expertise. Como señalan los autores, se trata de actores con ciertos saberes técnicos, acreditaciones académicas y trayectorias reconocidas a nivel local y global, quienes intervienen en distintos campos de conocimiento y expertise técnica. La particularidad reside en que no sólo movilizan conocimientos específicos, sino que también se constituyen como sujetos capaces de intervenir en la construcción de determinadas interpretaciones de la cuestión social, de construir ciertos problemas como públicos, de ofrecer alternativas para su solución e, incluso, de incidir en las agendas públicas de debate o las políticas de gobierno.

7. Retomando discusiones antropológicas centrales del siglo XX, Nussbaumer y Cowan Ros (2011) caracterizan a los mediadores sociales como agentes (técnicos, políticos, religiosos) que intervienen en la interconexión y construcción de mundos diferenciados, como entre el universo de las políticas públicas y los espacios locales (Nussbaumer y Cowan Ros, 2011: 50-55). Los autores destacan la importancia de prestarle atención a las interacciones que acontecen entre mediadores sociales y distintos actores sociales (mediados), propiciando reconstruir los saberes y repertorios, los recursos materiales y simbólicos, y la producción de significados que se hilvanan en la construcción de la realidad social.

8. Seguimos la caracterización de Diana Milstein(2009) sobre eventos 
Hornes, M. - Saberes, tramas y significados del dinero: una aproximación...

significativos. Se trata de reconstruir aquellas interacciones sociales en las cuales los actores enfrentan situaciones significativas, pero que no dejan de ser eventos relacionados a los acontecimientos cotidianos dentro de los cuales se encuentran inmersos. (Milstein, 2009: 47-48).

9. El Área Metropolitana de Buenos Aires (AMBA) está conformada por la Ciudad Autónoma de Buenos Aires y 24 partidos que componen el conurbano. El partido de Avellaneda es el primer partido ubicado en sentido Sur, lindante con la Ciudad Autónoma de Buenos Aires. El mismo posee una superficie total de $54 \mathrm{~km} 2$, y una población estimada en 342.000 habitantes, según el último censo poblacional realizado por el Instituto Nacional de Estadísticas y Censos (INDEC).

10. En su momento de mayor magnitud -mediados del año 2003- el Jefes y Jefas alcanzó a transferir 3.052 millones de pesos, alcanzando a 2 millones de beneficiarios (Cogliandro, 2010).

11. Valor aproximado a los 170 dólares estadounidenses según la cotización actual de la moneda en la República Argentina.

12. Monto aproximado de 64 dólares estadounidenses según la cotización actual de la moneda en la República Argentina.

13. Se puede consultar el documento en línea de ANSES: "La Asignación Universal Por Hijo para Protección Social en perspectiva". Abril 2012. Disponible en línea: http://observatorio.anses.gob.ar/publicacion 14. El programa "Jóvenes" utilizaba las siguiente variables para definir los distintos niveles de vulnerabilidad de los adolescentes: Situación de pobreza del hogar (N. B. I y L. P)- Clima educativo del hogar- Presencia en el hogar de niños y/o jóvenes que (estando en edad de asistir) no asisten a ningún establecimiento educativo- Hogares con jefes con problemas de inserción en el mercado de trabajo- Vulnerabilidad demográfica- Vulnerabilidad por fecundidad adolescente- Vulnerabilidad por jefatura adolescente con hijos menores.

\section{Referencias Bibliogràfícas}

ANSES (2012) "La Asignación Universal Por Hijo para Protección Social en perspectiva”. Disponible en línea: http://observatorio. anses.gob.ar/publicacion 
AGIS Y CAÑETE. Agis, E. Cañete, C y Panigo, D. (2010) El impacto de la Asignación Universal por Hijo en la Argentina. Ceil- Piette/ CONICET. Documentos Publicados. [en línea, disponible en: www. ceil-piette.gov.ar/docpub/documentos/AUH_en_Argentina.pdf

BANCO MUNDIAL. (2009) Transferencias Monetarias Condicionadas: Reduciendo la pobreza actual y futura. EEUU, Washington, DC. BLOCH, M. y Parry, J. (eds.) (1989). Money and morality of exchange. Cambridge: Cambridge University Press.

BOHANNAN, P. (1967) The impact of money on an African Subsistence Economy. En Dalton, G. (ed.) Tribal and Peasant Economies. Readings in Economic Anthropology, pp. 123-35. New York: The Natural History Press.

CECCHINI, S. y MADARIAGA, A. (2011). Programas de transferencias condicionadas: balance de la experiencia reciente en América Latina y El Caribe. Cuadernos de la CEPAL Nro. 95. Santiago de Chile. Chile. COGLIANDRO, G. (2010) Análisis del gasto público social en el presupuesto nacional 2010. En Documentos de Trabajo $n^{\circ}$ 1, Fundación Siena. [Disponible en línea: http://www.iefpa.org.ar/info/2010/analisis.pdf] CRUCES, G. ROVNER, H. (2008). Los programas sociales en la opinión pública: Resultados de la Encuesta de Percepción de los Planes Sociales en la Argentina. En Los programas sociales en Argentina hacia el Bicentenario. Visiones y perspectivas. Banco Mundial [Disponible en línea: www.bancomundial.org.ar ]

DALTON, G. (1967) Primitive Money. EnDalton, G. (ed.) Tribal and Peasant Economies. Readings in Economic Anthropology, pp. 25481. New York: The Natural History Press.

DODD, N. (1994). The sociology of money. Cambridge: Polity.

DUBOIS, V. (2014) The Economic Vulgate of Welfare Reform: Elements for a Socioanthropological Critique. Current Anthropology, Vol. 55, Crisis, Value, and Hope: Rethinking the Economy (August 2014), pp. S138-S146. FRANZONI, J. (2008) Transferenciascondicionadas e igualdad de género: ¿Blancos, negros o grises? En: Rev. CienciasSociales 122: 115-131. GUYER, J. (edit) (1994) Money Matters: Instability, Values and Social Payments in the Modern History of West African Communities. London: Elsevier. 
Hornes, M. - Saberes, tramas y significados del dinero: una aproximación...

HART, K. (2004) Money: One Anthropologist's View. En Carrier, J. (ed.) Handbook of Economic Anthropology. Massachussetts: Edward Elgar Plubishing Limited.

HORNES, M. (2015)"Transferencias monetarias condicionadas: reflexiones sobre las políticas sociales y los significados del dinero", en Revista Escenarios $n^{\circ} 22$, abril. p.p. 45-56.

HORNES, M. (2014a) "Etnografiar políticas sociales. Reflexiones de una conversión disciplinar". En: Anuario de Antropología Social y Cultural en Uruguay, Vol. 12: 215-228. (agosto 2014).

HORNES, M. (2014b) Transferencias condicionadas y sentidos plurales: el dinero estatal en la economía de los hogares argentinos. En: Revista Antípoda $\mathrm{N}^{\circ}$ 18- Antropología y economía II- abril 2014. Pág. 61-83. HORNES, M. (2013) Transferencias monetarias condicionadas (TMC): de los saberes expertos a los sentidos plurales del dinero. Tesis de Maestría en Antropología Social. Instituto de Desarrollo Económico y Social. Instituto de Altos Estudios Sociales de la Universidad Nacional de San Martín.

Instituto Nacional de Estadística y Censos de la República Argentina. (2014) Información disponible en línea: http://www.sig.indec.gov.ar/censo2010/ KLIKSBERG, B. Y NOVACOVSKY, I. (2015)El gran desafio. Romper la trampa de la desigualdad desde la infancia. Aprendizajes de la Asignación Universal por Hijo. Editorial Biblos.

MARCHIONNI, M y CONCONI, A. (2008) ¿Qué y a quién? Beneficios y Beneficiarios de los programas de transferencia condicionada de ingreso. En Los programas sociales en Argentina hacia el Bicentenario. Visiones y perspectivas. Banco Mundial. [Disponible en línea: www.bancomundial.org.ar ]

Ministerio de Economía de la Nación (2009). Nota técnica n ${ }^{\circ} 23$ : Asignación Universal por Hijoen Argentina. Cuadernos de Empleo e Ingresos. [en línea. Disponible en: http://www.mecon.

gov.ar/peconomica/informe/notas_tecnicas/23\%20NOTA $\% 20$ TECNICA\%20Empleo\%20e\%20Ingresos\%20inf\%2070.pdf]

MILSTEIN, D. (2009) La Nación en la escuela. Viejas y nuevas tensiones políticas. Buenos Aires: Miño y Davila Editores. 
MORRESI, S y VOMMARO, G. (2011). Saber lo que se hace. Expertos y política en Argentina. Universidad Nacional de General Sarmiento/ Prometeo Libros: Bs. As.

NEIBURG, F. (2010) Os sentidos sociais da Economia. Em: Dias Duarte, L (org.) Horizontes daz

NEIBURG, F. (2008). Inflación, monedas enfermas y números públicos. En Revista Crítica en Desarrollo n ${ }^{\circ}$ 2, pp. 93- 130.

NUSSBAUMER, B. y COWAN ROS, C. (editores) (2011). Mediadores sociales en la producción de prácticas y sentidos de la política pública. Buenos Aires: Ediciones CICCUS.

RINGOLD, D. y ROFMAN, R. (2008). Argentina: Políticas de transferencias de ingresos hacia el Bicentenario. En Los programas sociales en Argentina hacia el Bicentenario. Visiones y perspectivas.Banco Mundial. [Disponible en línea: www.bancomundial.org.ar ]

TEBET MARINIS, M. (2014) Repertóriosmorais e estratégiasindividuais de beneficiários e cadastradores do BolsaFamília. Sociologia\&Antropologia. V.04.02 : 543-562 (Outubro), Rio de Janeiro. THÉRET, B. (2015) El trípode de la moneda; deuda, someranía y confianza. En: Wilkis, A. y Roig, A. (2015) (eds.) El laberinto de la moneda y las finanzas. La vida social de la economía. Editorial Biblos.

WEBER, F.y DUFY, C. (2009) Másallá de la GranDivisión. Sociología, economía y etnografía. Buenos Aires: Antropofagia.

WEBER, F. (2002) Práticaseconómicas e formas ordinárias de calculo. EmMana. Estudos de Antropologia Social 8 (2), pp. 151-182.

WILKIS, A. (2014) Sociología del crédito y economía de las clases populares. REVISTA MEXICANA DE SOCIOLOGIA; Lugar: MEXICO; Año: 2014 vol. 76 p. 225 - 252.

WILKIS, A. (2013) Las sospechas del dinero. Moral y economía en el mundo popular. Buenos Aires: Paidós.

ZELIZER, V. (2011). El significado social deldinero. Buenos Aires: Fondo de Cultura Económica.

ZELIZER, V. (2009). La negociación de la intimidad. Buenos Aires: Fondo de Cultura Económica. 